\title{
III
}

\section{MICROSCOPIC SLIDE PRECIPITATION TESTS FOR THE DIAGNOSIS AND EXCLUSION OF SYPHILIS}

\author{
By B. S. KLINE, M.D., Cleveland, Ohio, U.S.A.
}

From the Laboratory Department of Mount Sinai Hospital

(A summary of the work of the author and of the author in collaboration with A. M. Young, M.D., C. R. Rein, M.D., S. Littman, M.D., and B. Levine, M.D.)

[Dr. Kline has kindly contributed this article at the request of the Editors, to whom he left the choice of illustrations, from a number which he supplied. Some of the details in the illustrations are not quite in accordance with the later practice described in the text, but the differences should not cause any confusion.]

Microscopic Slide Precipitation Tests for the diagnosis and exclusion of syphilis with defibrinated whole blood, unheated serum, heated serum and spinal fluid respectively, employing relatively stable emulsions of a purified antigen, are more sensitive and no less specific than good Wassermann tests, and are therefore better guides in the early detection of syphilis and in its treatment. Furthermore, they are much simpler in detail, require much less time, and are easier to perform accurately than Wassermann tests.

The following table gives the clinical evaluation of 9,000 microscopic slide precipitation tests and somewhat fewer Wassermann tests with the same antigen. (I)

Table I. shows the greater sensitivity of the Microscopic Slide Precipitation Test in all stages of syphilis. Positive reactions in cases showing no evidence of syphilis were very few in both tests and were probably due to technical errors.

A comparison of microscopic slide precipitation tests and Wassermann tests by others (2) has likewise shown the greater sensitivity of the slide tests. 


\section{MICROSCOPIC SLIDE PRECIPITATION TESTS}

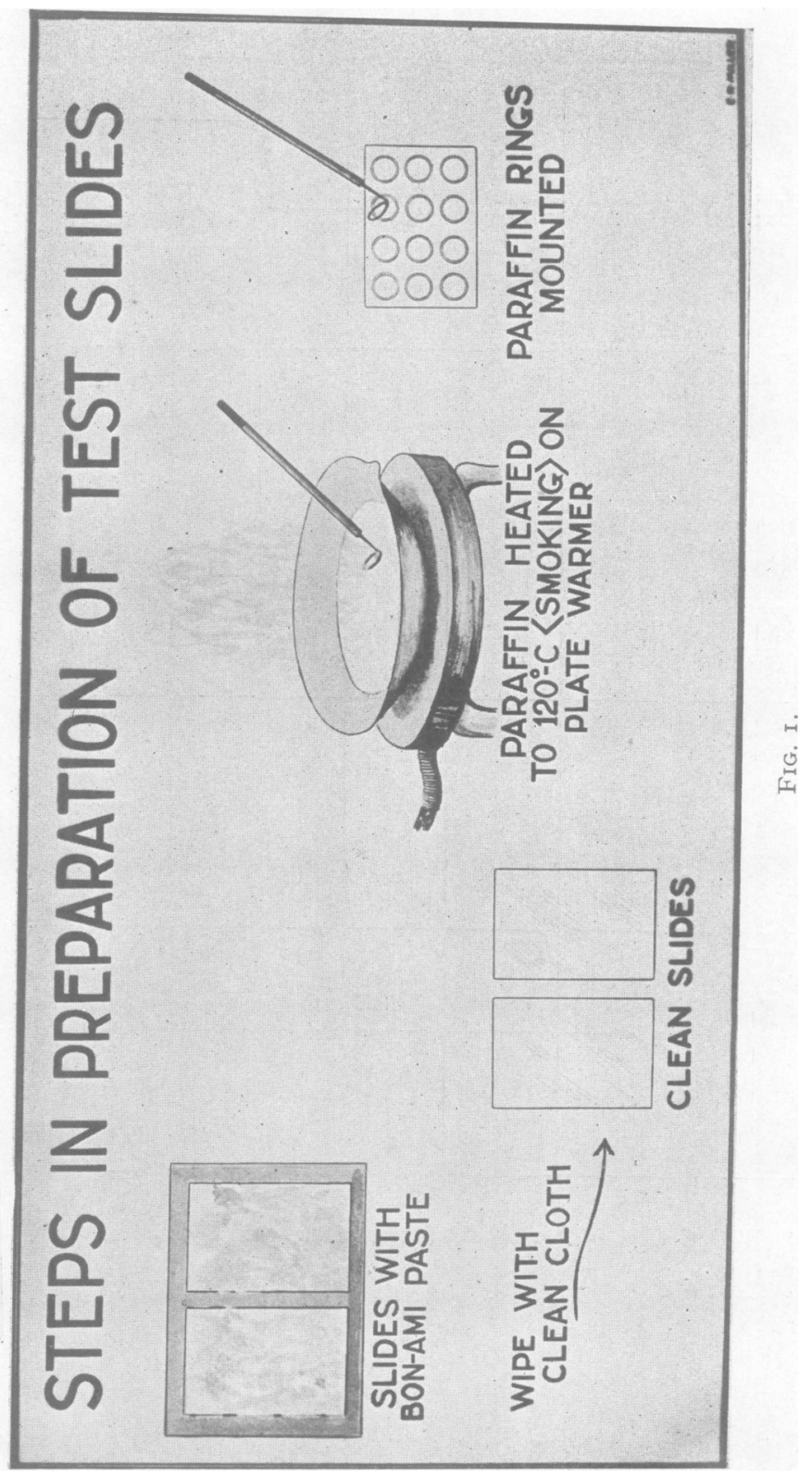




\section{BRITISH JOURNAL OF VENEREAL DISEASES}

\section{Table I.-Clinical Evaluation of Micro- \\ WASSERMANN TESTS}

\begin{tabular}{|c|c|c|c|c|c|c|c|c|}
\hline & \multirow{4}{*}{ Total tests. } & \multirow{4}{*}{$\begin{array}{c}\text { Tests in } \\
\text { cases with } \\
\text { history un- } \\
\text { obtainable, } \\
\text { data insufi- } \\
\text { cient, or } \\
\text { syphilis } \\
\text { doubtful. }\end{array}$} & \multirow{4}{*}{$\begin{array}{c}\text { Agree- } \\
\text { ment. }\end{array}$} & \multirow{4}{*}{$\begin{array}{c}\text { Total } \\
\text { disagree- } \\
\text { ment. }\end{array}$} & \multirow{2}{*}{\multicolumn{4}{|c|}{$\begin{array}{r}\text { Disagree- } \\
\text { False }\end{array}$}} \\
\hline & & & & & & & & \\
\hline & & & & & \multicolumn{2}{|c|}{ Primary. } & \multicolumn{2}{|r|}{ Treated } \\
\hline & & & & & $\begin{array}{c}\text { Un- } \\
\text { treated. }\end{array}$ & Treated. & $\begin{array}{l}\text { Secon- } \\
\text { dary. }\end{array}$ & $\begin{array}{l}\text { Ter- } \\
\text { tiary. }\end{array}$ \\
\hline \multirow[t]{2}{*}{$\begin{array}{l}\text { VERY SEN- } \\
\text { SITIVE } \\
\text { SLIDE TEST. }\end{array}$} & $\begin{array}{l}\text { 90or } \\
\text { (1 } 86 \text { I syphilitic } \\
\text { sera } \pm \text { to } \\
++ \text { in slide, } \\
\text { Wassermann } \\
\text { or both tests } \\
20.85 \% \text { ). }\end{array}$ & . & & & & & & \\
\hline & & 76 & $\begin{array}{c}8829 \\
98 \cdot 92 \%\end{array}$ & $\left|\begin{array}{c}96 \\
\mathbf{r} \cdot 08 \%\end{array}\right|$ & o & $\begin{array}{c}3 \\
0.033 \%\end{array}$ & $\begin{array}{c}2 \mathrm{I} \\
0.24 \%\end{array}$ & $\begin{array}{c}55 \\
0.61 \%\end{array}$ \\
\hline \multirow[t]{2}{*}{$\begin{array}{l}\text { VERY SEN- } \\
\text { SITIVE } \\
\text { WASSER- } \\
\text { MANN TEST } \\
\text { (A) }\end{array}$} & & & & & & & & \\
\hline & $875^{8}$ & 76 & $\mid \begin{array}{c}8421 \\
96 \cdot 99 \%\end{array}$ & $\begin{array}{c}26 \mathrm{I} \\
3.01 \%\end{array}$ & $\begin{array}{c}3 \\
0.03 \%\end{array}$ & $\begin{array}{c}4 \\
0.05 \%\end{array}$ & $\begin{array}{c}70 \\
0.81 \%\end{array}$ & $\begin{array}{c}\text { I } 5 \mathrm{I} \\
\mathrm{I} \cdot 74 \%\end{array}$ \\
\hline $\begin{array}{l}\text { SENSITIVE } \\
\text { SLIDE TEST }\end{array}$ & 8897 & 76 & $\begin{array}{c}8649 \\
98 \cdot 05 \%\end{array}$ & $\left|\begin{array}{c}172 \\
\mathrm{I} \cdot 95 \%\end{array}\right|$ & o & $\begin{array}{r}4 \\
0.04 \%\end{array}$ & $\begin{array}{c}42 \\
0.48 \%\end{array}$ & $\begin{array}{c}109 \\
\mathrm{r} \cdot 24 \%\end{array}$ \\
\hline $\begin{array}{l}\text { SENSITIVE } \\
\text { WASSER- } \\
\text { MANN TEST } \\
\text { (B). }\end{array}$ & 8513 & 76 & $\begin{array}{c}7769 \\
92 \cdot 08 \%\end{array}$ & $\mid \begin{array}{c}668 \\
7 \cdot 92 \%\end{array}$ & $\begin{array}{c}3 \\
0 \cdot 04 \%\end{array}$ & $\begin{array}{c}6 \\
0.07 \%\end{array}$ & $\begin{array}{c}160 \\
I \cdot 90 \%\end{array}$ & $\begin{array}{r}426 \\
5 \cdot 05 \%\end{array}$ \\
\hline
\end{tabular}

(A) About $35 \%$ of tests with $0.2 \%$ cholesterinised antigen ; about $65 \%$ with $0: 3 \%$ cholesternised antigen.

(B) About 35\% of tests with noncholesterinised antigen; about $65 \%$ with $0.0,5 \%$ cholesternised antigen.

The test in its various forms applied to $(a)$ heated serum, (b) unheated serum, (c) defibrinated finger blood (for diagnosis and for elimination of syphilis), and (d) spinal fluid respectively, is carried out as follows :- 


\title{
MICROSCOPIC SLIDE PRECIPITATION TESTS
}

\author{
scopic Slide Precipitation Tests AND \\ W.ith The SAme Antigen.
}

\begin{tabular}{|c|c|c|c|c|c|c|c|c|}
\hline \multicolumn{3}{|l|}{ ments. } & \multicolumn{6}{|r|}{ - } \\
\hline \multicolumn{3}{|l|}{ negatives. } & \multicolumn{6}{|c|}{ Positive reactions-no evidence of syphilis. } \\
\hline \multicolumn{3}{|l|}{ syphilis. ' } & \multirow[b]{2}{*}{ Total. } & \multicolumn{2}{|c|}{ Slide test. } & \multicolumn{2}{|c|}{$\left|\begin{array}{c}\text { Wasser- } \\
\text { mann test. }\end{array}\right|$} & \multirow[b]{2}{*}{ Clinical diagnosis. } \\
\hline C. N.S. & $\begin{array}{c}\text { Con- } \\
\text { genital. }\end{array}$ & $\begin{array}{l}\text { Not } \\
\text { deter- } \\
\text { mined. }\end{array}$ & & $\begin{array}{c}\text { Sensi- } \\
\text { tive. }\end{array}$ & $\begin{array}{c}\text { Very } \\
\text { sensi- } \\
\text { tive. }\end{array}$ & $\begin{array}{c}\text { Sensi- } \\
\text { tive. }\end{array}$ & $\begin{array}{c}\text { Very } \\
\text { sensi- } \\
\text { tive. }\end{array}$ & \\
\hline $0.033 \%$ & $\mid \begin{array}{c}\text { I } \\
0.01 \%\end{array}$ & $0.033 \%$ & $\mid \begin{array}{c}10 \\
0.11 \%\end{array}$ & $\begin{array}{l}+ \\
\pm \\
\pm \\
\pm \\
0 \\
+ \\
\pm \\
= \pm \\
\pm \\
-\end{array}$ & $\begin{array}{l}++ \\
+ \\
+ \\
+ \\
+ \\
+ \\
+ \\
+ \\
+ \\
+\end{array}$ & $\begin{array}{l}- \\
- \\
\overline{-} \\
\overline{-} \\
\overline{0} \\
- \\
-\end{array}$ & $\begin{array}{l}\overline{-} \\
\pm \\
0 \\
\pm \\
- \\
- \\
- \\
-\end{array}$ & $\begin{array}{l}\text { Cervicitis, vaginal discharge. } \\
\text { Chronic pelvic inflammatory disease. } \\
\text { Pregnancy. } \\
\text { Acute pharyngitis. } \\
\text { Lysol poisoning, mitral stenosis. } \\
\text { Lysol poisoning. } \\
\text { Bartholin cyst. } \\
\text { Cirrhosis of liver. } \\
\text { Neurasthenia. } \\
\text { Diabetes mellitus. }\end{array}$ \\
\hline $0.08 \%$ & $\mid \begin{array}{c}1 \text { I } \\
0.13 \%\end{array}$ & $\stackrel{9}{0.10 \%}$ & $\begin{array}{c}6 \\
0 \cdot 07 \%\end{array}$ & $\begin{array}{l}- \\
- \\
- \\
\bar{o}\end{array}$ & $\begin{array}{l}- \\
\overline{-} \\
\pm \\
-\end{array}$ & $\begin{array}{l}+ \\
\pm \\
- \\
\\
-\end{array}$ & $\begin{array}{l}+ \\
+ \\
+ \\
+ \\
+ \\
+\end{array}$ & $\begin{array}{l}\text { Miliary tuberculosis. } \\
\text { Pregnancy. } \\
\text { Neurasthenia. } \\
\text { Influenza } \\
\text { Pleurisy with effusion (TBC ?) } \\
\text { Carcinoma of bladder. }\end{array}$ \\
\hline $0.04 \%$ & $\begin{array}{c}6 \\
0.07 \%\end{array}$ & $\begin{array}{c}6 \\
0.07 \%\end{array}$ & I $\stackrel{\text { I }}{0} \%$ & + & ++ & - & - & Cervicitis, vaginal discharge. \\
\hline $\begin{array}{c}16 \\
0 \cdot 19 \%\end{array}$ & $\begin{array}{c}26 \\
0.31 \%\end{array}$ & $\begin{array}{c}29 \\
0.34 \%\end{array}$ & $\frac{2}{0.02} \%$ & - & $\overline{-}$ & $\dot{+}$ & $\begin{array}{l}+ \\
\pm\end{array}$ & $\begin{array}{l}\text { Miliary tuberculosis. } \\
\text { Pleurisy with effusion (TBC ?) }\end{array}$ \\
\hline
\end{tabular}

\pm to ++ any test in syphilitic serum $=$ agreement.

Negative test in syphilitic serum, other test \pm to $++=$ false negative.

+ to ++ any test in nonsyphilitic serum $=$ false positive.

- is negative.

\pm is doubtful.

+ is positive.

++ is strongly positive.

\section{Materials for Microscopic Slide Precipitation TESTS FOR SYPHILIS.}

Sera.-These are prepared as for the Wassermann test, care being exercised that they contain no red blood cells 


\section{BRITISH JOURNAL OF VENEREAL DISEASES}

or foreign particles. After the unheated serum tests are finished, the sera (with the I c.c. pipettes originally used still in the tube) are heated at $56^{\circ} \mathrm{C}$. in a water bath for one half hour.

Defibrinated Finger Blood (see Fig. 9).-The patient's

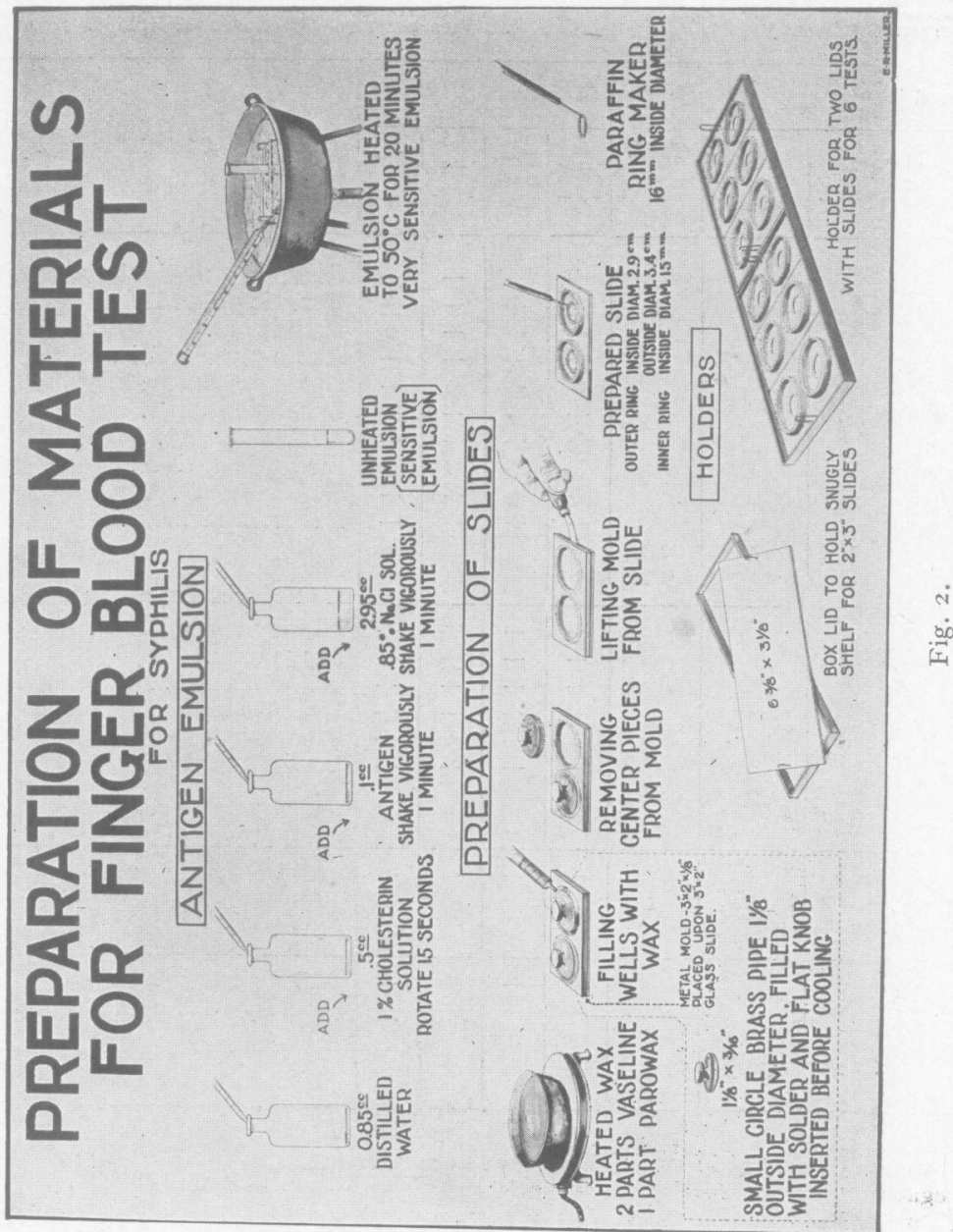

finger tip is cleaned with alcohol, sponged dry, and one or two puncture wounds made with a sharp needle. With the patient's hand in a dependant position, the bleeding finger is squeezed with both hands and the blood allowed to fall into a small vial $(3.5 \times \mathrm{r} .5 \mathrm{~cm}$.). The blood in the vial is then stirred with the flat end of a wooden toothpick until defibrinated (several minutes). The vial is then 


\section{MICROSCOPIC SLIDE PRECIPITATION TESTS}

stoppered with a cork, properly labelled, and kept in the refrigerator (at about $10^{\circ} \mathrm{C}$. preferably) until the blood is to be tested. (From a few minutes to twenty-four hours after collection.)

Glassware.-Microscopic slides $2 \times 3$ inches (Fig. I) as purchased, are rubbed on both sides with bon ami paste (prepared by breaking up a cake of bon ami in a small

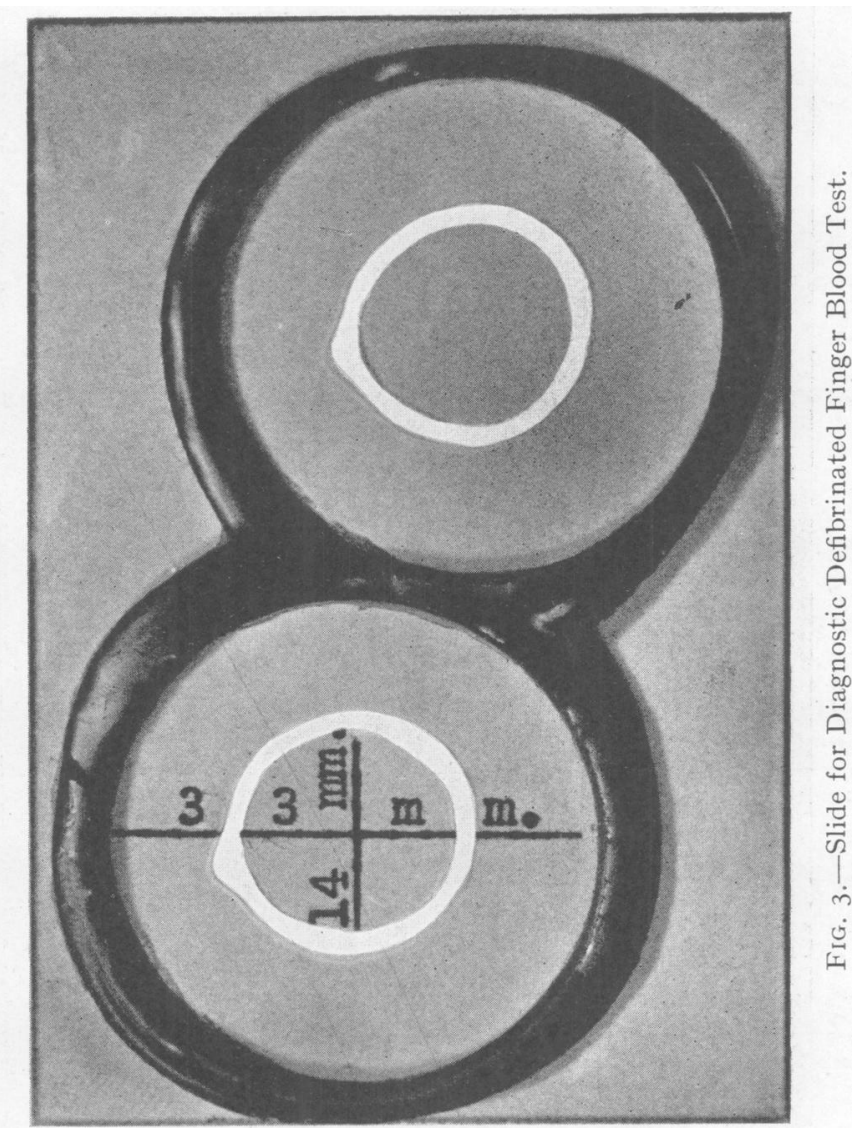

quantity of hot water). As soon as the paste is dry (in about five minutes) it is completely removed from the slide with a soft muslin cloth. For convenience the slides covered with paste may be stuck to each other, allowed to dry, and cleaned at any time.

For the unheated serum test, three paraffin rings, each with an inside diameter of $14 \mathrm{~mm}$., and three with an inside diameter of. $22 \mathrm{~mm}$., are mounted (Fig. 5). 


\section{BRITISH JOURNAL OF VENEREAL DISEASES}

For the heated serum test, twelve paraffin rings (Fig. I), each with an inside diameter of $\mathrm{I} 4 \mathrm{~mm}$., are mounted.

For the spinal fluid and for diagnostic defibrinated finger blood test, two rings, adjoining one another, are formed on each slide, as follows (Figs. 2 and 3) : Upon the clean slide a steel mold $3 \frac{2}{16} \times 2 \frac{3}{16} \times \frac{1}{8}$ inches with two

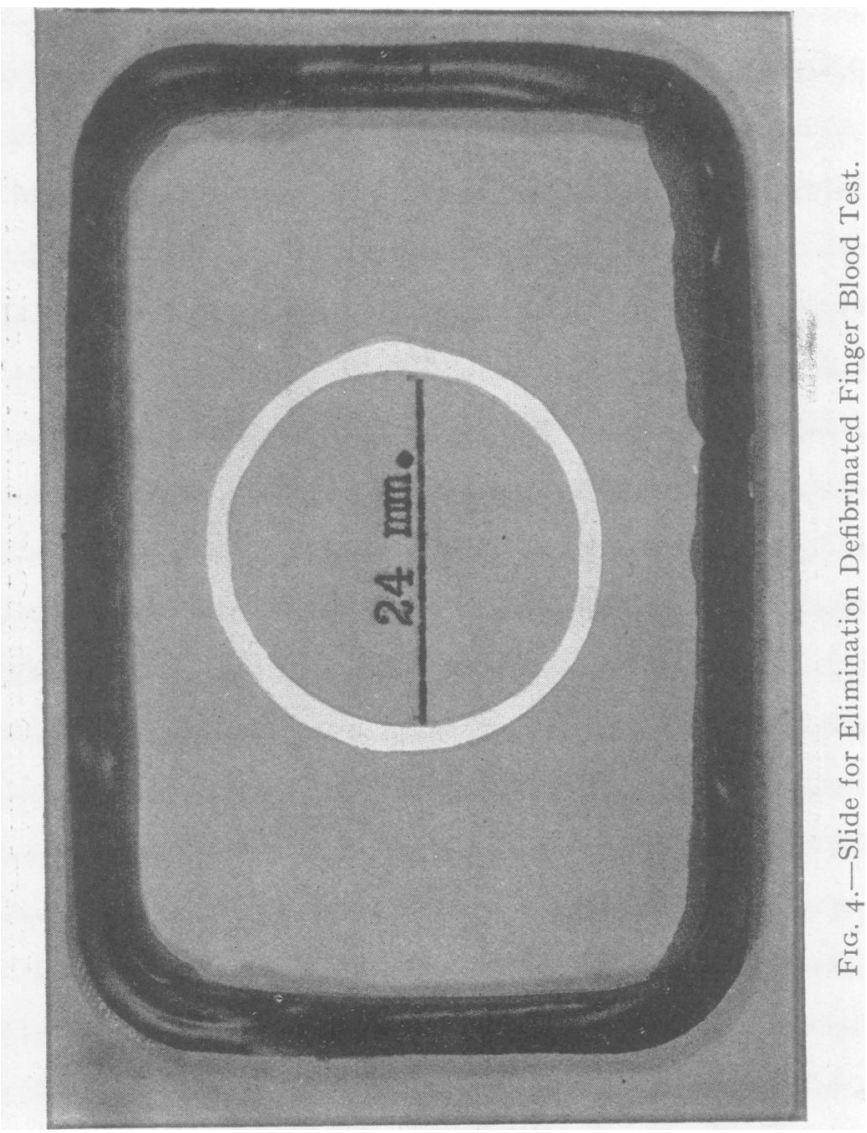

central wells $\mathrm{I}_{1 \mathrm{9}} \mathrm{i}$ inches in diameter is placed. A metal disc $I_{16}^{5}$ inches in diameter and $\frac{3}{16}$ inch thick is then placed in the centre of each well. The space between them is filled with hot wax (2 parts ordinary vaseline and I part parowax) from a Io c.c. glass syringe. After the mixture has cooled, the mold is removed by inserting a thin blade between it and the slide. [This completes the slide for the spinal fluid test.-Ed.] 


\section{MICROSCOPIC SLIDE PRECIPITATION TESTS}

For diagnostic finger blood tests, inner rings (I4 mm. inside diameter) are made on these slides (Fig. 3) with hot parowax by means of a thread-wound, wire loop, I5 mm. inside diameter, as described below.

The mold for the exclusion defibrinated finger blood test slides (Fig. 4) is $3 \frac{1}{16} \times 2 \frac{1}{8} \times \frac{1}{8}$ inches, with one rectangular well $2 \frac{3}{4} \times 1 \frac{7}{8}$ inches. The inner plate is $2 \frac{3}{8} \times I_{16}^{9} \times \frac{1}{8}$ inches. The space between them is filled with hot wax, as described above. The inner ring (inside diameter $24 \mathrm{~mm}$.) is made with hot parowax by a threadwound wire loop of proper size.

Instrument for making Paraffin Rings.-This is essentially the instrument proposed by Green (8) (Figs. I and 5).

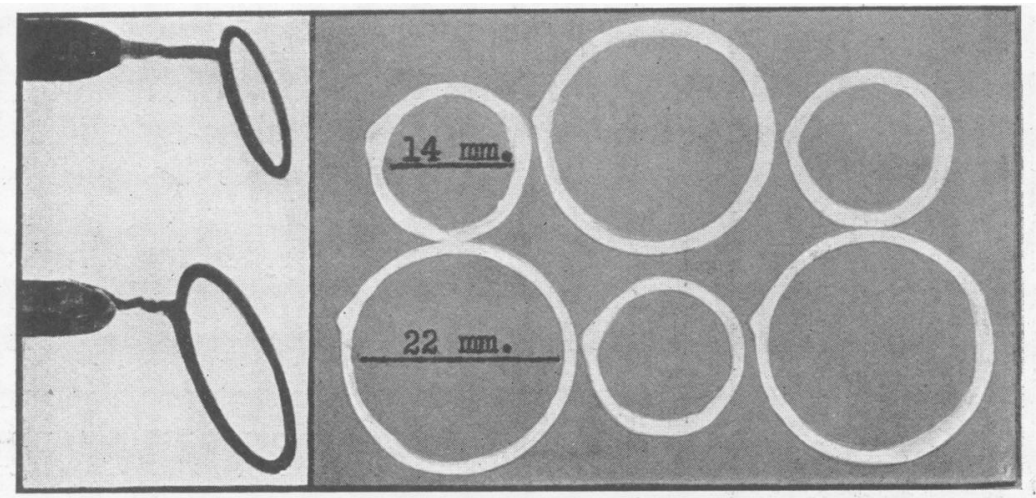

FIG. 5.-Slide for Diagnostic and Elimination Tests of Unheated Serum.

A piece of soft iron wire (No. 28) is wound twice tightly about a test tube (about $\mathrm{I}_{5} \mathrm{~mm}$. in outside diameter), forming a double loop and leaving a double shaft about an inch in length. The two shafts are then twisted together to within a $\frac{1}{4}$ inch of the free end. After removing the looped wire from the test tube, a piece of linen thread (No: I2) is started from the free end of the shaft after being fastened here by a single twist of the two free ends. Three long turns are made reaching the loop, which is then tightly wound with the thread. The winding is continued up the shaft to the free end, where it is fastened between the two ends of the wire by twisting them. The loop is then bent at right angles to the shaft and reshaped by working the loop against the bottom of the test tube mentioned above. The shaft is then 


\section{BRITISH JOURNAL OF VENEREAL DISEASES}

inserted into the handle of a teasing needle, or into straight hemostatic forceps.

This is the loop to make the proper-sized rings for diagnostic and exclusion heated serum tests, diagnostic unheated serum and finger blood tests. A loop about

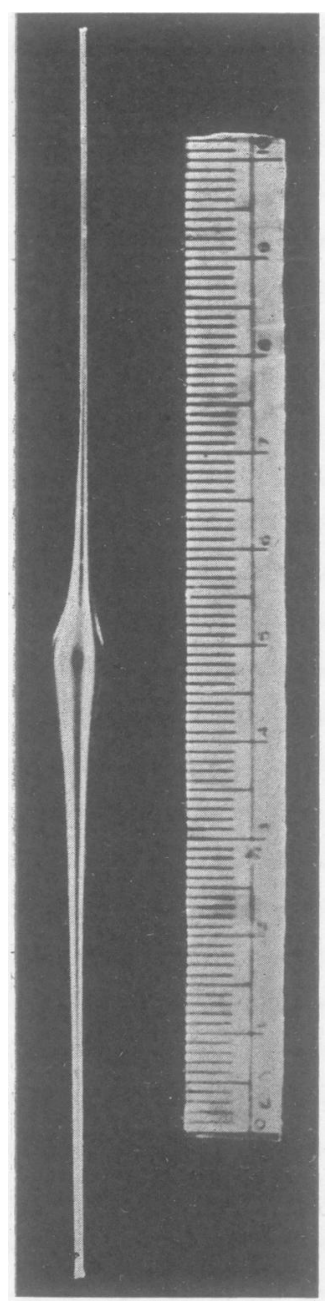
$23 \mathrm{~mm}$. in outside diameter is used to make the rings for the unheated serum exclusion test, and one about $25 \mathrm{~mm}$. in outside diameter to make the rings for the exclusion finger blood test.

The paraffin rings are made by dipping the instrument into smoking paraffin (about $120^{\circ}$ C.), draining quickly at one point and transferring the remainder to the glass slide.

Slide-Holders (for three $3 \times 2$ inch slides). - The slide-holder is a . wooden lid of a slide box $\left(3 \frac{1}{2} \times\right.$ $6 \frac{3}{4}$ inches) containing an easily fitting thin wooden shelf having a small handle at each end. The I. holder for the two slide-holders which consists of a wooden lid $\left(I 3 \times \frac{5}{8} \times 3 \frac{1}{2} \times \frac{1}{2}\right.$ inch inside, I4 $\frac{1}{2}$ $\times 4 \frac{1}{2} \times I$ inch outside measurements) makes it possible to use six slides at one time.

Pipettes.-The pipettes needed for delivery of sera, defibrinated finger blood, spinal fluid, and for preparing the antigen emulsions are the ordinary finely graduated 0.2 to Io c.c. pattern. That for the 3 per cent. salt solution, the $3 \frac{1}{2}$ per cent. salt solution, and the $I$ per cent. acetic acid solution is 0.2 c.c., graduated in 0.00 c.c. For delivering the antigen emulsions Wright pipettes are used. They are made from glass tubing 6 to Io $\mathrm{mm}$. in diameter with the tubes about $\frac{1}{2} \mathrm{~mm}$. in diameter, delivering a drop equal to about 0.008 c.c. (62 drops per $\frac{1}{2}$ c.c.). A 25 -c.c. pipette graduated in $0 \cdot I$ or I c.c. is used to deliver the distilled water to lake the blood in the finger blood tests. 


\section{MICROSCOPIC SLIDE PRECIPITATION TESTS}

Salt Solution.-Sodium chloride (C.P. or reagent, Merck) solutions used in the test are $0.85,3$ and $3 \frac{1}{2}$ per cent. These are prepared with distilled water having a $p \mathrm{H}$ of about 6 . Such water gives a lilac colour when I drop of chlorphenol red indicator (La Motte) is added to 0.25 c.c. of it in a small chamber. Distilled water having a $p \mathrm{H}$ of $5 \cdot 2$ or less gives a yellow colour with this indicator, and is not satisfactory.

One per cent. Acetic Acid.-This solution is made just before use from glacial acetic acid. It is advisable to use no less than I c.c. of acid (delivered from a $I$ or 2 c.c. pipette), and accordingly 99 c.c. of distilled water.

Antigen.-The purified antigen (3) is a lipid obtained from chilled absolute ethyl alcohol extract of beef heart muscle powder by precipitation in acetone at $50^{\circ}$ to $37^{\circ} \mathrm{C}$. It is prepared as follows (see Fig. 7) :-

Two hundred grams of dried heart powder (Difco) is placed in a 2-litre Erlenmeyer flask.

One litre of absolute ethyl alcohol (99 per cent.) is added.

After the flask is stoppered with a cork covered with tinfoil, it is shaken vigorously by hand at intervals for two hours. Better still, two wide-mouth bottles (Difco bottles for I-lb. beef heart powder), each with Ioo gm. of beef heart powder and 500 c.c. of absolute ethyl alcohol (99 per cent.), are shaken vigorously in a machine for two hours. (This short extraction removes almost all of the desired antigenic substance in the powder.)

The extract is filtered into a litre cylinder through good grade filter paper of medium texture (Schleicher and Schull, No. 597, $32 \mathrm{~cm}$.).

During filtration the mixture is stirred with a wooden tongue depressor and toward the end pressed with the cork until the powder is quite dry.

The extract (about 775 c.c.) is placed in the refrigerator at $8^{\circ}$ to $10^{\circ} \mathrm{C}$. for twenty-four hours.

During this time a fairly heavy white precipitate settles out. This is filtered off and the filtrate in a large evaporating dish is concentrated on a water-bath at $45^{\circ}$ to $50^{\circ} \mathrm{C}$. determined by a thermometer bulb within the extract. During evaporation of the alcoholic extract an irregular festoon appears at the periphery. When the extract reaches the proper concentration the festoon disappears, and the margin of the concentrated extract is sharp. 


\section{BRITISH JOURNAL OF VENEREAL DISEASES}

The extract is now poured quickly into 500 c.c. of acetone C.P. (Coleman and Bell) at $50^{\circ} \mathrm{C}$. in a large evaporating dish.

The dish is then placed in an air incubator at $37^{\circ} \mathrm{C}$. for

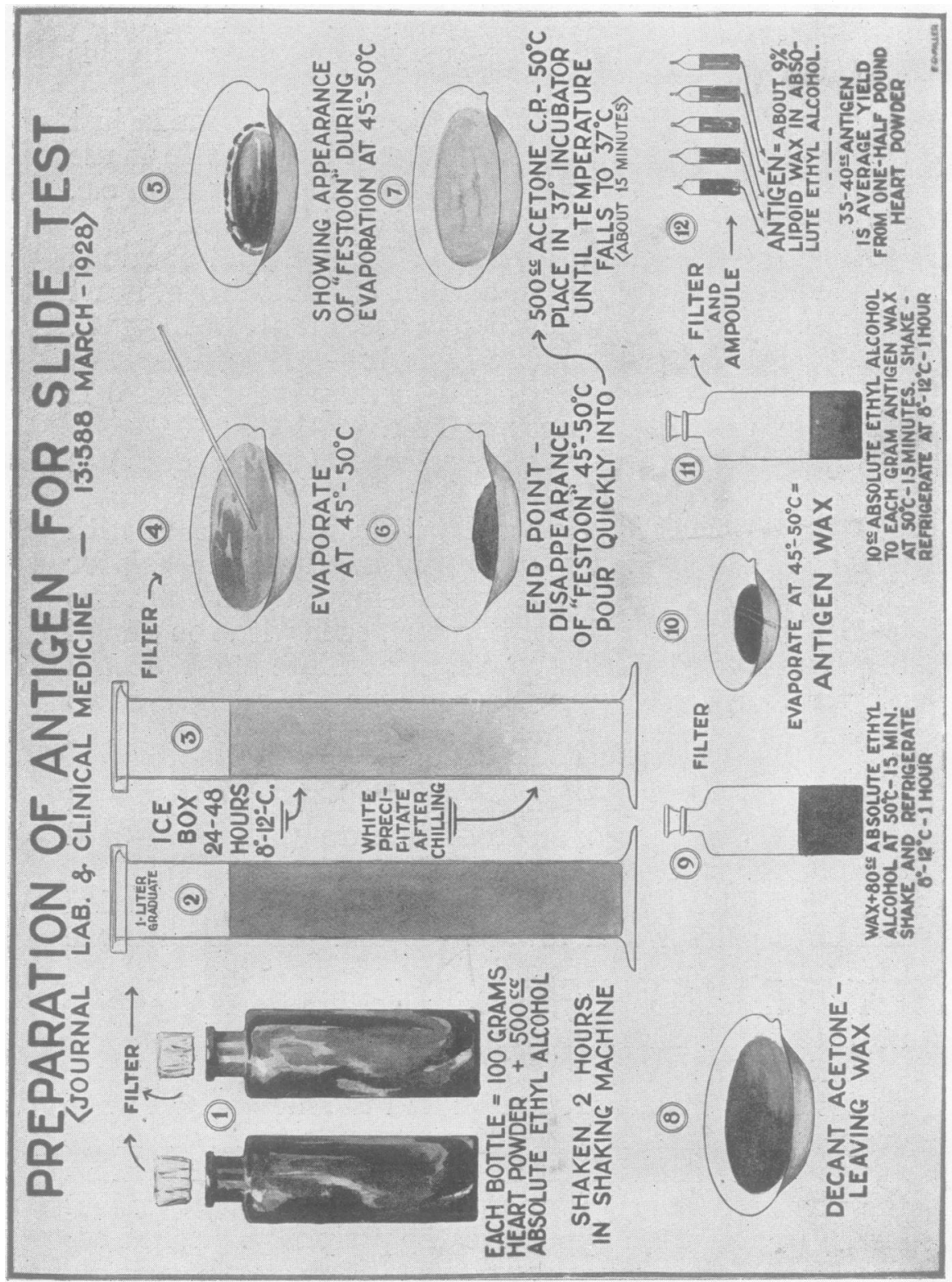




\section{MICROSCOPIC SLIDE PRECIPITATION TESTS}

fifteen minutes, after which the acetone is decanted, leaving a. soft, yellow brown wax adherent to the side of the dish.

This is placed on a water-bath, or in an air incubator, at $50^{\circ} \mathrm{C}$. until the little acetone remaining has evaporated (about thirty minutes).

The wax is then worked together and placed in a glassstoppered bottle ; 80 c.c. of absolute ethyl alcohol (99 per cent.) that has been kept in an air incubator at $50^{\circ}$ to $56^{\circ}$ for one half hour or longer is added, and after a few minutes' shaking the bottle is placed in an air incubator at $50^{\circ} \mathrm{C}$., shaken gently after fifteen minutes and again after thirty minutes, when it is removed from the incubator and placed in the refrigerator at $8^{\circ}$ to $10^{\circ} \mathrm{C}$. for forty-five minutes.

The solution is then filtered, and the filtrate is evaporated down at $45^{\circ}$ to $50^{\circ} \mathrm{C}$., resulting in a soft brown wax (antigen wax). The wax is weighed, and to each gram in a glass-stoppered bottle, ro c.c. of absolute ethyl alcohol (99 per cent.) (at $50^{\circ}$ to $56^{\circ} \mathrm{C}$.) are added. After the bottle has been shaken for a few minutes it is placed in an air incubator at $50^{\circ} \mathrm{C}$. for thirty minutes, and then shaken for a few minutes.

The slightly turbid solution is placed at $8^{\circ}$ to $10^{\circ} \mathrm{C}$. for an hour and then filtered. The resultant clear filtrate is the antigen, and contains about 8.75 per cent. of the alcohol-treated, acetone-insoluble wax.

The antigen is kept preferably in the incubator at $37^{\circ} \mathrm{C}$. in a glass-stoppered bottle.

The average yield of antigen wax from $\frac{1}{2} \mathrm{lb}$. of beef heart powder is 3.5 to $4 \mathrm{gm}$. The discarded acetonesoluble lipoidal residue (impurities) ordinarily weighs at least three times this amount.

The I per cent. cholesterin solution for the emulsions is prepared in about forty-five minutes by placing in an oven at $50^{\circ}$ to $56^{\circ} \mathrm{C}$. and shaking gently for a few minutes at fifteen-minute intervals.

\section{Discussion of Antigens}

Originally Kahn antigen dilutions were used in the slide test, but it was found that whereas the results were thoroughly reliable when the glassware and ingredients in the test were warm, a disturbing phenomenon occurred when the tests were done in a cold room. In slide tests 


\section{BRITISH JOURNAL OF VENEREAL DISEASES}

of non-luetic sera with the majority of Kahn antigen dilutions at low room temperatures a coarse granularity developed, and the tests were read as doubtful. Likewise non-luetic sera giving at most doubtful results at ordinary room temperatures gave false positive results at lower temperatures.

The non-cholesterinised Kahn antigen residue, obtained by evaporating off the alcohol of the extract by means of a fan, consists of a brown wax and a colourless oily substance. The latter, on standing, becomes granular and white, and apparently is the substance responsible for the disturbing phenomenon mentioned above. On the other hand, the dark brown waxy residue of the purified antigen for the slide tests obtained in a similar manner contains no appreciable amount of oily substance. Furthermore, in slide tests of non-luetic sera with purified antigen emulsions at temperatures as low as $8^{\circ} \mathrm{C}$. (in refrigerator), no alteration of the emulsion is visible, and the results are the same as at higher temperatures. Even more important is the fact that the purified antigen emulsions give weaker reactions at low temperatures, and sera giving doubtful reactions at ordinary room temperatures give negative results at lower temperatures.

The following is a comparison of the purified antigen emulsions and Kahn antigen dilutions in slide tests :-

\section{Purified Antigen EMULSIONS.}

(a) Satisfactory at low room temperatures as well as at ordinary ones.

(b) Relatively stable, satisfactory for at least forty-eight hours in heated serum tests.

(c) The diagnostic purified antigen emulsion is more sensitive and no less specific than Kahn antigen dilution.

(d) The purified antigen emulsions are more uniform in quality and quantity than are Kahn antigen dilutions.

Plain alcoholic antigens, or those following preliminary acetone or ether extraction, or those made by adding certain substances to an alcoholic extract of previously extracted tissue, prepared a number of times according 


\section{MICROSCOPIC SLIDE PRECIPITATION TESTS}

to a given formula, vary greatly in constituents and in concentration of desirable substances, not a few being unsatisfactory for use. The purified antigen prepared as described above, however, being of uniform quality, and of known concentration, gives best results in serum tests for syphilis, especially in the Microscopic Slide Precipitation Tests.

In working out the antigen emulsion formulas described below for the precipitation tests, it was found that not only the quantity of the ingredients, but also the order of their mixture is of the greatest importance. It is possible to secure uniformly satisfactory emulsions only when the cholesterin is precipitated before the antigen is added.

It was further observed that the sensitivity of the antigen emulsions is dependant more upon the cholesterin content than upon that of the antigen itself. Satisfactory emulsions may contain, in a total of 4.4 c.c., from 0.0375 to $0 \cdot$ I 5 c.c. of the antigen. The cholesterin content, on the other hand, must be more carefully titrated, since the more nearly it approaches the maximum dispersible in a given total, the more sensitive the emulsion becomes. Beyond this point the emulsions are unsatisfactory because of the presence of a non-dispersible precipitate.

It was noted that distilled water has a greater dispersing effect upon emulsions than has salt solution. On the other hand, emulsions containing electrolytes (salt solution, acetic acid), although they lose their antigenic properties sooner, give stronger precipitation reactions than those prepared with distilled water.

Concerning the influence of alcohol on the wax or in the emulsion, it was found that preparations from a concentrated alcoholic solution of the base (antigen) are most satisfactory, since they permit of the dispersion, in a given total, of much more cholesterin than those prepared with the same quantity of the base in from five to ten times the quantity of the alcohol. Furthermore, the emulsions with less alcohol are relatively stable, keeping (at room temperature) their antigenic properties undiminished for forty-eight hours. Much more stable than these, but less satisfactory for routine preparation, are emulsions made from the wax itself (no alcoholic dilution). These (at room temperature) retain their antigenic power for weeks. 


\section{BRITISH JOURNAL OF VENEREAL DISEASES}

Heating at $35^{\circ}, 50^{\circ}, 55^{\circ}$ and $60^{\circ} \mathrm{C}$. for fifteen minutes quantitatively increases the sensitivity of the emulsions. Observed through the microscope at a magnification of about 800 times, emulsions of antigen alone heated to $35^{\circ}, 50^{\circ}, 55^{\circ}, 60^{\circ} \mathrm{C}$. show quantitatively a swelling of the lipid globules.

Based upon the clinical evaluation of 9,000 tests as presented above, it seemed advisable to establish a level of sensitivity for a diagnostic slide test about midway between the sensitive and very sensitive tests. This has been accomplished by the use of a proper amount of cholesterin in the antigen emulsions. Furthermore, it seemed advisable to use a test even more sensitive than the very sensitive test to exclude more nearly syphilis in blood donors, in cases of suspicious sore, and syphilis under treatment. This additional sensitivity is secured by heating the antigen emulsion to $55^{\circ} \mathrm{C}$., and by using only the larger particles (obtained by centrifugation).

Preparation of Antigen Emulsion for Diagnostic and Exclusion Tests of Unheated Serum

\section{Formula :-}

0.85 c.c. distilled water $(p \mathrm{H}$ about 6$)$.

$I \cdot O$ c.c. I per cent. cholesterin (Pfanstiehl C.P. in absolute ethyl alcohol, 99 per cent.).

$0 \cdot$ I c.c. antigen.

2.45 c.c. 0.85 per cent. sodium chloride (C.P. or reagent, Merck) solution ( $p \mathrm{H}$ about 6$)$.

The technique of preparing the emulsion according to the above formula is as follows :

Into a I-Oz. bottle the required amount of distilled water $(p \mathrm{H}$ about 6$)$ is pipetted. (The $p \mathrm{H}$ of the water need not be determined for the preparation of heated serum test emulsions.)

The bottle is held at an angle, and the I per cent. cholesterin in absolute ethyl alcohol (99 per cent.) is allowed to run along the side of the neck of the bottle.

The bottle is gently rotated from the neck for twenty seconds.

It is held at an angle again, and the proper amount of antigen is pipetted against the side of the neck of the bottle from a finely graduated pipette. 


\section{MICROSCOPIC SIJIDE PRECIPITATION TESTS}

The bottle is promptly stoppered with a cork and shaken vigorously (the fluid thrown from bottom to cork and back) for one minute.

Lastly, the 0.85 per cent. sodium chloride solution is allowed to run in quite rapidly, the bottle is stoppered again and shaken less vigorously than previously for one minute.

The emulsion, when examined under the microscope at a magnification of about 120 , shows numerous very fine particles, but no clumps whatever.

The emulsions are heated in water-baths at temperatures shown below.

For Diagnostic Test. For Exclusion Test.

Place I c.c. of the above Place 4 c.c. of the above emulsion in a narrow test emulsion in a narrow test tube ( $12 \mathrm{~mm}$. inside dia- tube ( $22 \mathrm{~mm}$. inside diameter) in a water-bath at meter) in a water-bath at $55^{\circ} \mathrm{C}$. for fifteen minutes. $55^{\circ} \mathrm{C}$. for fifteen minutes, The emulsion as soon as then pour into a $3 \times I$ inch heated is ready for use.

tube and centrifuge for fifteen minutes (about a thousand R.P.M.). Decant the fluid and, with the tube inverted, dry the inside of the tube with a cloth almost to the level of the sediment.

To the sediment add 0.7 c.c. of 0.85 per cent. sodium chloride solution. $(p \mathrm{H}$ about 6). Transfer to a narrow tube for use.

These emulsions, if kept at room temperature, are satisfactory for use for six hours after preparation.

Preparation of Antigen Emulsions for Diagnostic and Exclusion Tests of Heated Serum

The emulsion has the same formula as that given above for the unheated serum tests. 


\section{BRITISH JOURNAL OF VENEREAL DISEASES}

For Diagnostic Test

Place I c.c. or more of the emulsion in a narrow test tube (I2 $\mathrm{mm}$. inside diameter) in a water-bath at $35^{\circ} \mathbf{C}$. (beaker of water in usual laboratory air incubator at about $37^{\circ} \mathrm{C}$.) for fifteen minutes. The emulsion as soon as heated is ready for use.
For EXcLusion Test

Place 2 c.c. of the emulsion in a narrow test tube (I2 $\mathrm{mm}$. inside diameter) in a water-bath at $55^{\circ} \mathbf{C}$. for fifteen minutes. Then pour into a $3 \times \mathrm{I}$ inch tube and centrifuge for fifteen minutes (about a thousand R.P.M.). Decant the fluid and, with the tube inverted, dry the inside of the tube with a cloth almost to the level of the sediment. To the sediment add 0.7 c.c. of 0.85 per cent. sodium chloride solution. Transfer to a narrow tube for use.

These emulsions, if kept at room temperatures, are satisfactory for use for forty-eight hours after preparation.

For routine use in unheated and heated serum tests, 8.8 c.c. of emulsion are made at one time by using double the amounts in the given formula, after which the quantities indicated above are placed in four narrow tubes and heated as outlined.

Preparation of Antigen Emulsions for Diagnostic and Exclusion Tests of Defibrinated Finger BLOOD

\section{Formula :}

0.85 c.c. distilled water ( $p \mathrm{H}$ about 6$)$.

I. 25 c.c. of I per cent. cholesterin (Pfanstiehl C.P.) in absolute ethyl alcohol (99 per cent.).

$\mathrm{O} \cdot \mathrm{I}$ c.c. antigen.

$2 \cdot 2$ c.c. of 0.85 per cent. sodium chloride (C.P. or reagent, Merck) solution ( $p \mathrm{H}$ about 6$)$.

Pour the emulsion into a narrow tube ( $12 \mathrm{~mm}$. inside diameter) and place in a water-bath at $35^{\circ} \mathrm{C}$. for fifteen minutes. Then pour the heated emulsion into a $3 \times$ I-inch tube and centrifuge for fifteen minutes (about a 


\section{MICROSCOPIC SLIDE PRECIPITATION TESTS}

thousand R.P.M.), and after decanting the fluid and drying the inner wall of the tube, add I c.c. of 0.85 per cent. sodium chloride solution ( $p \mathrm{H}$ about 6$)$. The emulsion prepared as just described is used for the exclusion test. The diagnostic test emulsion is prepared by diluting the exclusion test emulsion as follows :-

$0 \cdot 3$ c.c. exclusion test emulsion.

0.3 c.c. 0.85 per cent. sodium chloride solution $(p \mathrm{H}$ about 6).

These emulsions, if kept at room temperatures, are satisfactory for use for thirty hours after preparation.

Preparation of Antigen Emulsion for Diagnostic and Exclusion Tests of Spinal Fluid

The emulsion has the same formula as that given above for the defibrinated finger blood tests.

8.8 c.c. of the emulsion are made by using double the quantities given in the formula.

For Diagnostic Test

Place 4 c.c. of the emulsion in a narrow test tube (I2 $\mathrm{mm}$. inside diameter) in a water-bath at $35^{\circ} \mathrm{C}$. for fifteen minutes. Then pour into a $3 \times \mathrm{I}$ inch tube. Centrifuge for fifteen minutes (about a thousand R.P.M.). Decant the fluid and, with the tube inverted, dry the inside of the tube with a cloth almost to the level of the sediment. To the sediment add I c.c. 0.85 per cent. sodium chloride solution $(p \mathrm{H}$ about 6).

Transfer to a narrow test tube for use.

These emulsions, if kept at room temperature, are satisfactory for use for twenty-four hours.
For ExClusion Test

Place 4 c.c. of the emulsion in a narrow tube ( $12 \mathrm{~mm}$. inside diameter) in a waterbath at $45^{\circ} \mathrm{C}$. for fifteen minutes. Then pour into a $3 \times I$ inch tube. Centrifuge for fifteen minutes (about a thousand R.P.M.). Decant the fluid and, with inside of the tube with a cloth almost to the level of the sediment. To the sediment add I c.c. of 0.85 per cent. sodium chloride solution ( $p \mathrm{H}$ about 6$)$.

Transfer to a narrow test tube for use. the tube inverted, dry the 


\section{BRITISH JOURNAL OF VENEREAL DISEASES}

Diagnostic and Exclusion Microscopic Slide PRECIPITATION TESTS FOR SyPhilis WITH UNHEATED SERUM (4)

(I) Place three unheated serum test slides (Fig. 5) each with three large and three small chambers on a tray. On a second tray place three similar slides and place the two trays in a large holder. .

(2) Into each of the eighteen large rings pipette 0.03 c.c. of 3.5 per cent. sodium chloride solution ( $p \mathrm{H}$ about 6$)$ near the paraffin wall at one point.

(3) After the salt solution is pipetted into the large rings, the unheated sera to be tested are pipetted, first 0.05 c.c. into a small ring, then 0.1 c.c. into a large ring $(0.2$ c.c. is drawn up into the pipette, and after the $\mathrm{I} .5$ c.c. is delivered the remaining 0.05 c.c. is blown out, the pipette shaken vigorously five times and then reinserted into the tube of the unheated serum).

(4) After the sera are pipetted, a small drop (about 0.01 c.c.) of 3.5 per cent. sodium chloride solution is allowed to fall from a Wright pipette into the serum in each small ring.

(5) The slides in the holder are rotated on a flat surface with moderate vigour for one minute.

(6) Into each of the large chambers one small drop (about 0.008 c.c.) of exclusion test antigen emulsion is allowed to fall from a Wright pipette. Into each of the small chambers is allowed to fall a similar drop of the. diagnostic test antigen emulsion.

(7) The slides in the holder are rotated on a flat surface for four minutes.

(8) The results are examined at once through the microscope at a magnification of about r20 times (low power $16 \mathrm{~mm}$. objective, eyepiece $12 x$ ) with the light cut down as for the study of urinary sediments and reported in terms of pluses according to the degree of clumping and the size of the clumps.

Any spilling from the chamber makes the reaction therein unsatisfactory, and the serum concerned should be re-tested.

After the unheated serum tests are finished, the sera (with the I c.c. pipettes originally used still in the tubes) are heated in a water-bath at $55^{\circ} \mathrm{C}$. for one half hour. 


\section{MICROSCOPIC SLIDE PRECIPITATION TESTS}

Diagnostic and Exclusion Microscopic Slide PreCIPITATION TESTS FOR SYPhILIS WITH HEATED Serum (4), (5) (see Fig. 8)

(I) Place three heated serum test slides each with twelve small chambers on a tray in a small holder.

(2) Into each of a pair of the thirty-six rings, pipette

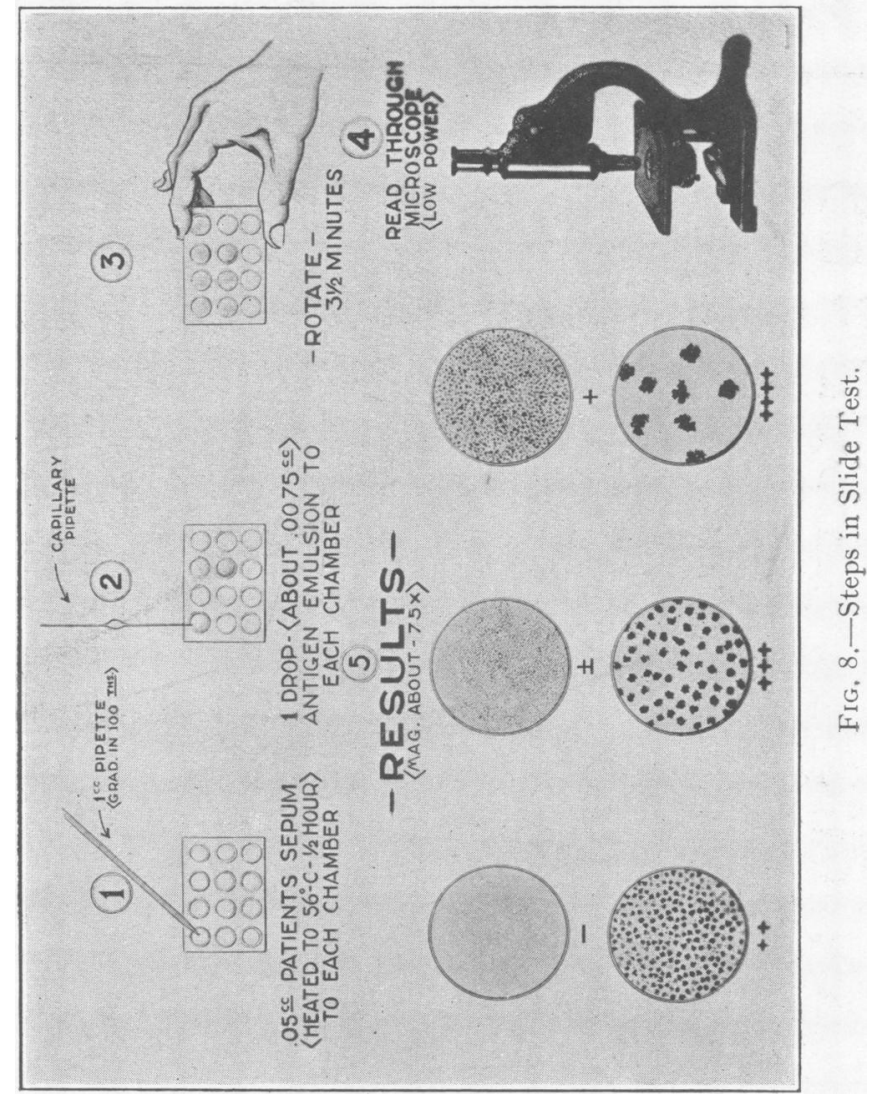

0.05 c.c. of the heated serum to be tested (eighteen sera in duplicate).

(3) After all the sera are pipetted, I drop of the diagnostic test antigen emulsion (about 0.008 c.c.) is allowed to fall from a Wright pipette into one of the two portions of each serum. Into each of the other eighteen duplicate sera is allowed to fall a similar drop of exclusion test antigen emulsion.

(4) The slides in the holder are rotated on a flat surface for four minutes. 


\section{BRITISH . JOURNAL OF VENEREAL DISEASES}

(5) The results are read at once through the microscope in the same way as are the unheated serum tests.

Diagnostic and Exclusion Microscopic Slide PreCIPITATION TESTS FOR SyPHILIS WITH DEFIBRINATED Finger Blood (4), (6)

(I) Place a finger blood test slide (Fig. 3) with two

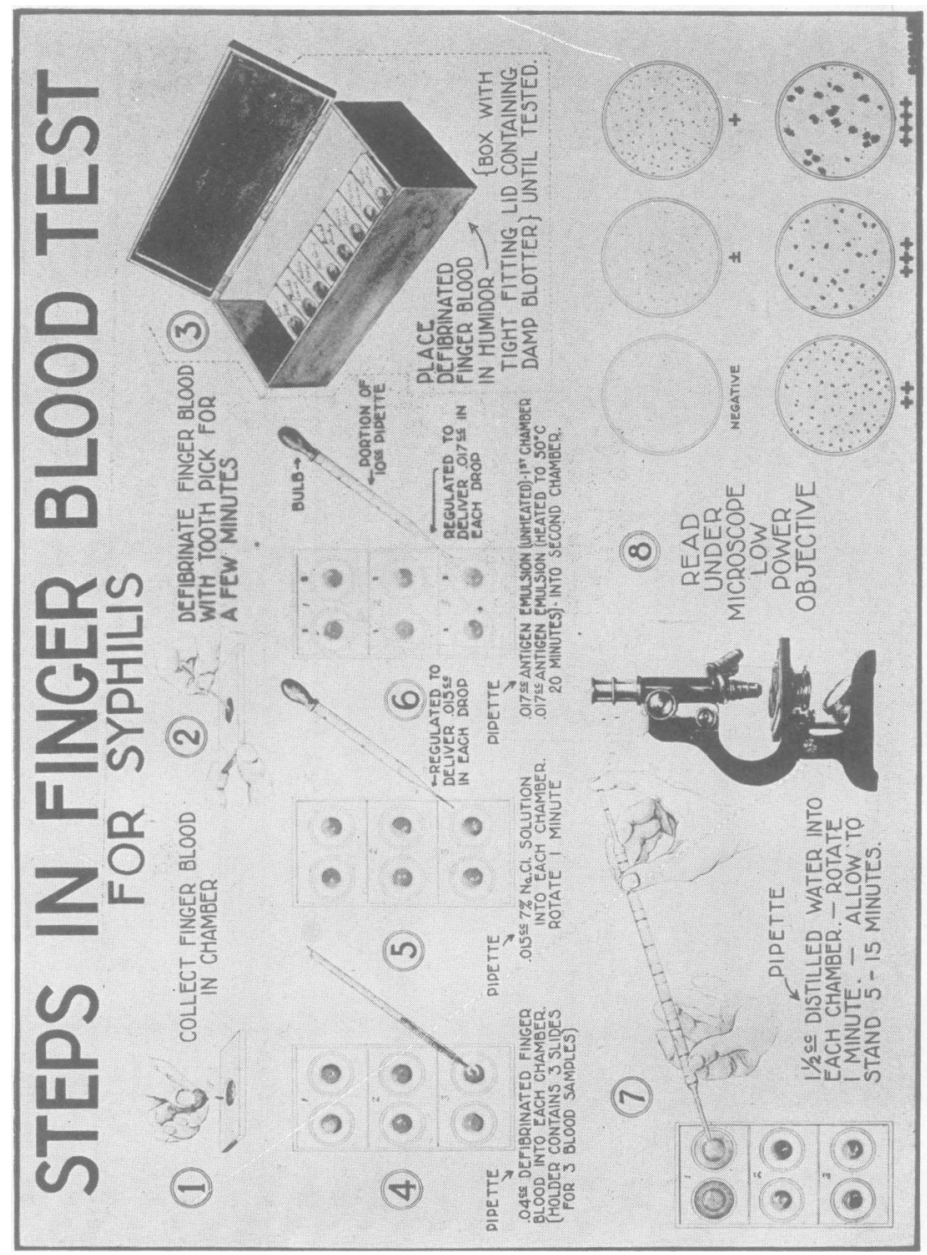

small chambers and two finger blood test slides (Fig. 4) each with a large chamber on a tray. On the second tray place three similar slides and place the two trays in a large holder.

(2) Pipette into each of the four large inner chambers 52 


\section{MICROSCOPIC SLIDE PRECIPITATION TESTS}

on four slides (Fig. 4) 0.05 c.c. of 3 per cent. sodium chloride solution ( $p \mathrm{H}$ about 6) close to the paraffin wall.

(3) Draw up 0.I7 c.c. of defibrinated finger blood and pipette 0.04 C.c. into a small inner chamber (Fig. 3) and O.I c.c. into a large inner chamber (Fig. 4), using the tip of the pipette to move the fluid to the limits of the inner chamber. Repeat the procedure with blood from additional cases.

(4) After the bloods are pipetted, a small drop (about o.oI c.c.) of 3 per cent. sodium chloride solution $(p \mathrm{H}$ about 6 ) is allowed to fall from a Wright pipette into the blood in each small chamber.

(5) The slides in the holder are rotated on a flat surface with moderate vigour for one minute.

(6) Into the large inner chambers, one small drop (about 0.008 c.c.) of exclusion test antigen emulsion is allowed to fall from a Wright pipette. Into each of the small inner chambers is allowed to fall a similar sized drop of the diagnostic test antigen emulsion.

(7) The slides in the holder are rotated on a flat surface for four minutes.

(8) Into the large chambers, 5 c.c. and into the small chambers 2 c.c. of distilled water are allowed to fall from a 25 c.c. pipette (graduated in 0. I c.c. or I c.c.).

(9) The fluids are agitated by moving the holder very gently (avoid spilling) for one minute.

(I0) ${ }^{-}$The results are examined at once, or at any time within fifteen minutes, in the same way as are those of the tests described above.

Diagnostic and Exclusion Microscopic Silde Precipitation Tests for Syphilis With SPINAL Fluid (7) (see FIG. Io)

Preliminary Procedures with Spinal Fluids

Spinal fluids, turbid with exudate, blood or bacteria, or containing injected substances including horse serum, are unsatisfactory for testing. Spinal fluids with slight turbidity or few particles are centrifuged at high speed for ten minutes, and the clear fluid is withdrawn or decanted.

Place the required number of test tubes, $6 \times \frac{5}{8}$ inch, each containing 5 c.c. of Benedict's solution (I926), in a beaker (Pyrex). Add water halfway to the top. Heat. Keep the tubes in vigorously boiling water for five minutes. 


\section{BRITISH JOURNAL OF VENEREAL DISEASES}

Place the tubes in a rack. After making certain that no copper reduction has occurred in any of the tubes, add to each tube, properly numbered, 0.5 c.c. of spinal fluid. Shake each tube vigorously for ten seconds.

Replace the tubes in the beaker. Add water halfway

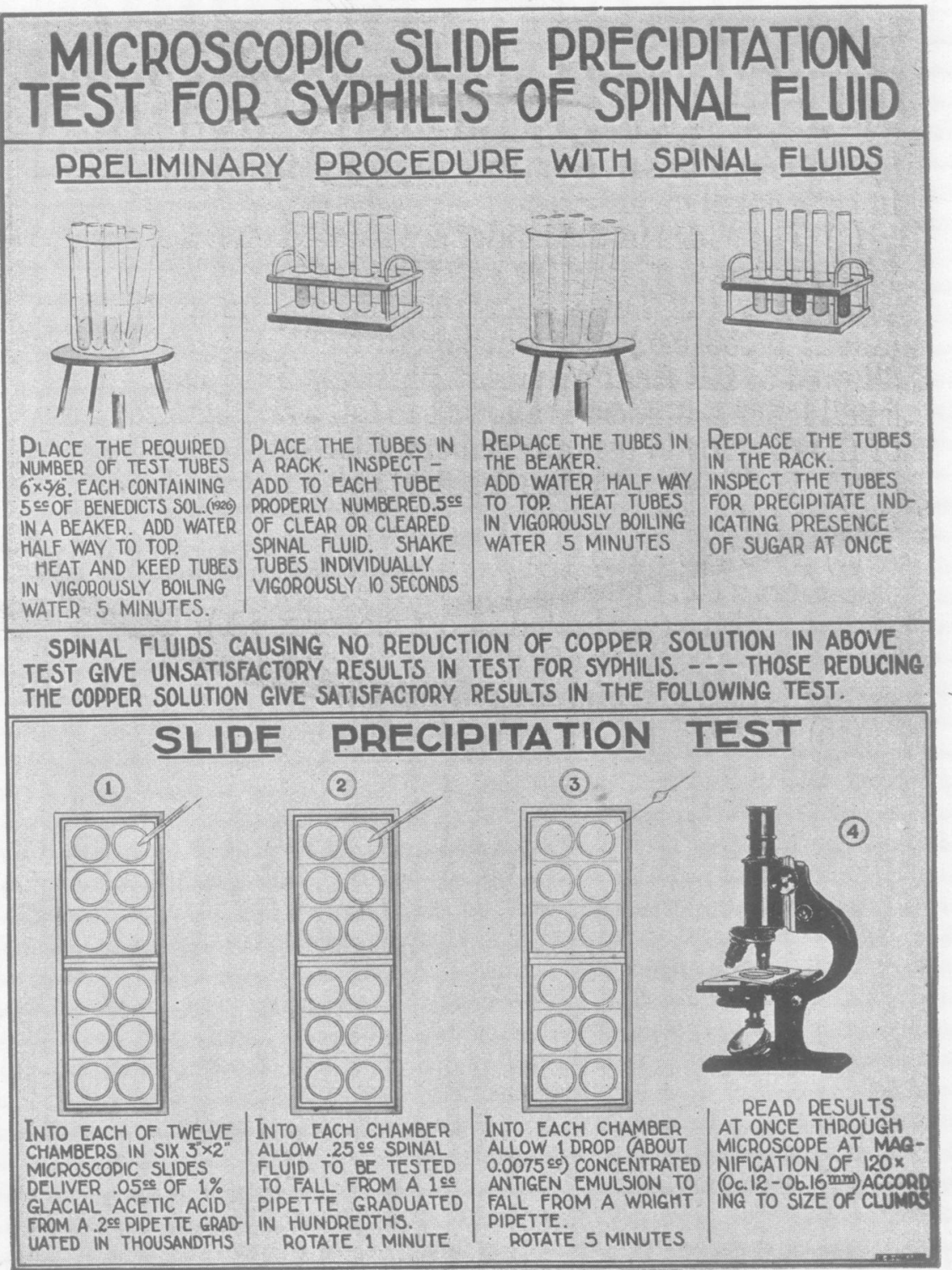

FIG. Io. 


\section{MICROSCOPIC SLIDE PRECIPITATION TESTS}

to the top. Heat. Keep the tubes in vigorously boiling water for five minutes.

Replace the tubes in the rack, inspecting each immediately after removing from the beaker, for precipitate indicating presence of sugar.

Spinal fluids giving a negative reaction for sugar in the above test are unsatisfactory for testing for syphilis. These are fluids that have been acted upon by bacteria either inside or outside of the body. In the former case in which organisms and ferments of the exudate have acted upon the sugar, the fluids may contain substances that give positive or unsatisfactory reactions in various tests for syphilis. Bacterial contamination subsequent to withdrawal of spinal fluids from cases of syphilis causes a steady loss both of sugar and of the specific reacting substance, if the fluids are kept at room temperature.

On the other hand, if spinal fluids containing sugar when withdrawn from the body are kept at low temperature $\left(8^{\circ}\right.$ to $10^{\circ} \mathrm{C}$. $)$, they continue to give a positive reaction for sugar with the test described above for several weeks, and syphilitic spinal fluids under these conditions show no appreciable loss of specific reacting substance for at least a week.

The clear and cleared spinal fluids which give a positive reaction in the sugar test described above are then tested as follows :-

Into each of twelve chambers on six glass slides (in a holder tilted slightly by placing a small metal bar, $\frac{1}{8}$ inch thick, under one long side) deliver 0.05 c.c. of I per cent. glacial acetic acid solution from a $0 \cdot 2$ c.c. pipette graduated in thousandths.

Into each of two chambers allow 0.25 c.c. of the spinal fluid to be tested (six spinal fluids in duplicate) to fall from a I c.c. pipette graduated in hundredths. (Hold the pipette directly above the acid and lastly touch the tip of the pipette at some dry portion of the chamber.)

Rotate the slides in the holder on a flat surface with moderate vigour for one minute.

Into each chamber containing one of the two portions of each spinal fluid allow I drop (about 0.008 c.c.) of diagnostic antigen emulsion to fall from a Wright pipette, and into each of the duplicate spinal fluids I drop (about 0.008 c.c.) of exclusion antigen emulsion. 


\section{BRITISH JOURNAL OF VENEREAL DISEASES}

Rotate the slides in the holder on a flat surface with moderate vigour for one minute to distribute the antigen and then for four minutes move the holder gently but rapidly (about three complete movements a second) back and forth a distance of $\frac{1}{4}$ to $\frac{1}{2}$ inch.

The results are examined at once in the same manner as described above. (For ease in reading the results, the slide is tilted on a piece of metal $\frac{1}{8}$ inch thick, $\frac{1}{2}$ inch wide, and 4 inches long, placed on the stage.)

\section{Discussion OF THE TESTS}

The precipitation tests requiring the least precautions are those for testing heated sera. In these it is not necessary to determine the $p \mathrm{H}$ of the water and salt solution, and, furthermore, the antigen emulsions are satisfactory for use for forty-eight hours.

Because of their great sensitivity, the exclusion tests may occasionally be positive in cases with no evidence of lues and should therefore not be used for diagnosis. On the other hand, these very sensitive tests, when negative, are of greater value in indicating absence of syphilis than are tests of ordinary sensitivity.

\section{BIBLIOGRAPHY}

(I) Kline, B. S., and Littman, S. : “ Clinical and Serological Comparison of Microscopic Slide Precipitation Tests for Syphilis and Wassermann Tests with the same Antigen," J. Lab. and Clin. Med., 15, Ioo8, July, r930.

(2) Miller, Thomas H. : "The Kline Slide Precipitation Test for Syphilis : A Comparison with the Kolmer Modification of the Wassermann Test and the Kahn Precipitation Tests ; with a Clinical Evaluation in Syphilitic and Non-syphilitic Cases," Amer. Jour. of Syphilis, 13, 583 , October, I929.

Topd, L. C. : "The Clinical Comparison of Complement Fixation and Flocculation Tests," Southern Med. Jour., 22, ro7o, December, I929.

OGlesby, Marcella, and Knapp, Harold J.: "Comparative Studies in the Laboratory Diagnosis of Syphilis," Amer. Jour. of Public Health, 18, I5I9, December, I928.

(3) Kline, B. S. : " An Antigen for Use in Serum Tests for Syphilis," J. Lab. and Clin. Med., 13, 588, March, r928.

(4) Kline, B. S. : "Microscopic Slide Precipitation Tests for the Diagnosis and Exclusion of Syphilis," J. Lab. and Clin. Med. (in press).

(5) Kline, B S., and Young, A. M. : "A Microscopic Slide Precipitation Test for Syphilis" (second communication), J. Lab. and Clin. Med., 12, 477, February, I927. 


\section{MIC ROSCOPIC SLIDE PRECIPITATION TESTS}

(6) Kline, B. S., and Levine, Benjamin : “ I,ooo Precipitation Tests for Syphilis with Small Quantities of Defibrinated Finger Blood " (Clinical and Serological Comparison), J. Lab. and Clin. Med., 15, 768, May, I930.

(7) Kline, B. S., and Rein, C. R. : “The Microscopic Slide Precipitation Test for Syphilis with Spinal Fluid," J. Lab. and Clin. Med. (in press).

(8) Green, G. : " Paraffin Rings on Microscopic Slides," Amer. Jour. Public Health, 15, 65I, I925. 